\title{
Saudi Online Courtship Script: Qualitative Interviews of Using Matrimonial Websites among Saudi Users
}

\author{
Ayman Bajnaid ${ }^{1}$, Giuseppe Alessandro Veltri², Ala'a Hamdi Gharibeh ${ }^{3} \&$ Mahmoud Maqableh $^{4}$ \\ ${ }^{1}$ Communication Department, Faculty of Media and Communication King Abdulaziz University, Jeddah, Saudi \\ Arabia \\ ${ }^{2}$ Department of Sociology and Social Research, The University of Trento, Italy \\ ${ }^{3}$ Ala'a Hamdi Gharibeh, A Graduate Student of Management Information Systems, Amman Arab University, \\ Faculty of Business, Amman, Jordan \\ ${ }^{4}$ Management Information Systems, School of Business, The University of Jordan, Jordan \\ Correspondence: Mahmoud Maqableh, Associate Professor of Management Information Systems, School of \\ Business, The University of Jordan, Amman, Jordan. Tel: 962-6535-5000. E-mail: maqableh@ju.edu.jo
}

Received: May 12, 2018 Accepted: September 20, 2018 Online Published: October 29, 2018

doi:10.5539/mas.v12n11p223 URL: https://doi.org/10.5539/mas.v12n11p223

\begin{abstract}
While traditional Saudi Arabian courtship is rigidly structured according to Islamic codes of conduct, Saudis over the past decade have increasingly turned to unconventional means, e.g., matrimonial websites, to find and court a potential spouse. Using qualitative semistructured interviews $(\mathrm{N}=36)$, the analysis of the data revealed four main categories that demonstrate the reasons behind Saudis joining matrimonial websites: more opportunities, freedom from the limitations of offline interactions in Saudi culture, personal reasons, and encouragement.
\end{abstract}

Keywords: quantitative interviews, matrimonial websites, Saudi users

\section{Introduction}

Saudi Arabian culture is considered the most conservative in the Islamic world; cultural norms and religious values are so intertwined that it becomes difficult to distinguish between them (Al-Lily, 2011; Al Azmi et al., 2012; AlDuhaish et al., 2014; Mirah, and Masa'deh, 2014; Darawsheh et al., 2016; Alnajrani et al., 2018). Following their religious beliefs regarding the importance of protecting people from seduction, Saudis maintain gender segregation in all aspects of their daily lives, and it is considered one of the pillars of Saudi society. Such segregation between genders is also in line with Arabic norms, which tend to equate family honour with the honour of men's sisters and daughters. Therefore, Saudi society restricts direct interactions with unrelated members of the opposite sex. While it is considered a normal practice in Western societies, having a friendship or romantic relationship with a member of the opposite sex is highly unacceptable in conservative Saudi Arabia. The only acceptable form of relationship between unrelated members of the opposite sex in Saudi Arabia is marriage. This may explain why most marriages in Saudi Arabia are arranged marriages (Al-Romi and Al-Saeg, 2004) and why mate selection is considered a family and community affair between two families, rather than between partners (Hamon and Ingoldsby, 2003). With the advances in online connectivity, virtual platforms offer innovative spaces that facilitate the establishment and development of interpersonal relationships, thereby increasing and enhancing social interaction worldwide (Bargh and McKenna, 2004). They have opened the possibility of cross-gender communication between unrelated people in gender-segregated societies such as Saudi Arabia (Madini, 2012). These online settings include forums, chat rooms, social media platforms, and Saudi matrimonial websites (Al-Saggaf and Weckert, 2004). Among these virtual spaces, matrimonial websites have become increasingly attractive to Saudis because they help them find potential spouses in an unconventional way (Al-Saggaf, 2013).

Matrimonial and dating websites have become increasingly popular in recent years (Al-Saggaf, 2013), and a considerable number of people have gone on a date with a person they met through a dating website (Sprecher, Schwartz, Harvey, and Hatfield, 2008) or found a spouse via a matrimonial website (Al-Saggaf, 2013; Maqableh et al., 2015). Non-Muslim scholars tend to use the concepts of dating, mating, and matrimony interchangeably to convey finding a partner. However, matrimonial sites differ from dating sites. Matrimonial websites offer users a relatively safe setting to meet other marriage seekers and communicate with them concerning the possibility of 
finding a spouse while maintaining their religious commitments. However, most dating websites provide dating opportunities that may not lead to marriage. Thus, not all users of dating websites are searching for a potential spouse; some may be searching for a boyfriend or girlfriend. Dating websites focus on "dating or enabling two persons to meet and engage in mutually agreed upon social activities." In contrast, matrimonial sites focus on "bringing together two people who have a serious intention of getting married" (Al-Saggaf, 2013: 176). For these reasons, it is best to use "matrimonial" when talking about Muslim users and "dating" when talking about nonMuslim users. Mating could refer to both Muslim and non-Muslim users. Both dating and matrimonial websites provide access to a significant number of user profiles. These profiles can include pictures, written biographies, and short video clips. People can interact with one another via e-mail prior to meeting in person. Another feature of these websites is the ability to search for specific criteria in a potential partner (e.g., ethnicity, religion, height, body type; Whitty, 2008). These features allow for users to make comparisons between profiles. Unlike in an offline environment, impression formation in the online dating setting starts before the couple physically meets. Users consider their profiles résumés through which they attempt to market their "best" selves (Heino, Ellison, and Gibbs, 2005). Therefore, individuals may spend a considerable amount of time creating attractive profiles that will generate a positive impression on viewers. As a result, aspects such as screen name, profile photo, personal information, personal preferences, and description are heavily edited to provide the best impression possible. In other words, users tend to put a great deal of effort into creating flattering profiles (Whitty, 2010).

Through these matrimonial websites, Saudis can, perhaps for the first time, access the profiles of thousands of potential spouses. This process is significantly different from the traditional courtship practice, in which the first impression of a potential spouse is normally formed through the parents' or a matchmaker's description of the candidate's personality and physical attributes (Al-Khateeb, 2008; Al-Anzi, 2009; Bajnaid \& Al-Saggaf, 2017; Bajnaid \& Elyas, 2017; Bajnaid \& Elareshi, 2018). The first direct interaction in the traditional courtship process also takes place at a later stage in the presence of the female's guardian; this is when the couple and their families decide whether the marriage is suitable. However, by constructing their own online profiles on matrimonial websites, Saudis control the impressions they wish to leave on a future spouse, and they can be selective regarding the attributes they wish to reveal. According to Walther (1996), due to its asynchronicity, this online setting allows users to be strategic by lessening the potential partner's access to undesirable attributes, because they can form, manage, and modify their self-presentation more consciously than in initial face-to-face meetings. This paper provides an in-depth description of the actions Saudi marriage seekers follow when looking for spouses through matrimonial websites. Based on data collected from interviews, this paper details the model of the Saudi courtship process initiated online. The structure of the paper is as follows. Section 2 presents the research methodology used in this study. Section 3 states the data analysis. Research results are presented in Section 4. Section 5 concludes the paper.

\section{Research Methodology}

This research aims to provide answers about the Saudis' script of the courtship process; thus, the participants were interviewed about the scripts they followed as they moved toward marriage with a potential spouse. Because the targeted sample comprises Saudi users of matrimonial websites living in Saudi Arabia, their geographic dispersion makes it difficult, if not impossible, to interview them in person due to the economic costs and time, especially given that the current study has a fixed timeline and budget. To avoid these limitations, the researchers conducted online interviews with participants using Skype. This program allows researchers to conduct interviews with highquality voice and video over the Internet (James and Busher, 2009). The current study benefited from online interviews by extending access to the participants in comparison with offline interviews. Online interviews through Skype offer a safe, comfortable environment for both the researchers and participants. It could also be argued that online interviews present the opportunity to provide richer information regarding participants' attitudes, beliefs, and perceptions than face-to-face interviews, as some research suggests that people feel more confident and have higher levels of self-disclosure in online discussions (Joinson, 2001). It should be noted that most of these studies focused on discussion of computer-mediated communication in general and anonymity in particular; however, online interviews still have a certain degree of anonymity. The major limitation for online interviews is the absence of social cues (James and Busher, 2009). When face-to-face communication is not possible, it is essential to determine how it affects participants' knowledge construction and how researchers "can be sure about the authenticity and identity of online contributions beyond what they are told by their participants" (Hammersley, 2006: 8). However, the authenticity and identity of the current sample are assured, as they are members of a matrimonial website that required identity verification prior to joining.

\subsection{Interview Questions}

The current research uses a semistructured interview because it enables researchers to explore the phenomenon 
under investigation from the research population's perspective. A major advantage of this method is that it allows the interviewees to clearly communicate with participants and overcome ambiguities during the interview (Wojnar and Swanson, 2007). It also allows for collecting in-depth data due to flexibility in the data collection process (Silvermann, 1993). Unlike unstructured interviews, semistructured interviews enable the researcher to use instructions to guide the interview process. They also enable him or her to obtain reliable and comparable qualitative data that assist in identifying the similarities and differences between participants' responses. This also aids in forming a deep understanding of the phenomena because the interview questions are prepared in advance; thus, the researcher is prepared and appears competent when conducting the interview. It also enables participants to express their views in their own terms. As stated earlier, the goal of this study is to gain a detailed understanding of the courtship script of Saudi users using matrimonial websites to answer the main research question: What is the script Saudi users follow when trying to find a potential spouse through matrimonial websites?

\subsection{Pilot Study of the Interview}

A pilot study was conducted with ten volunteer Saudi members of a matrimonial website (five males and five females), aged between 21 and 57 (mean $=34.30$ years, $\mathrm{SD}=12.77$ ). The pilot study was conducted prior to the main study to identify any questions that could have been ambiguous or made participants uncomfortable. A pilot study also helps in forming operational procedures and discussing emergent problems prior to conducting research. For instance, throughout the pilot interviews, the researchers found that the interview question "Describe in detail the steps you followed when you moved from the website to other modes of interaction until you got married with a potential spouse" needed to be clarified because it was not clear to the interviewees whether they should also talk about the other communication methods they used until they met their potential spouse in person. Thus, the interview question was modified: "Describe in detail the steps you followed when you moved from the website to other modes of interaction with a potential spouse, up to the point of getting married."

\subsection{Administration of the Interviews}

The criterion to determine the sample size for a qualitative data analysis is that the number of cases must be large enough to achieve saturation, meaning that the data become repetitive and contain no new categories or emergent themes after a certain number of cases have been analysed (Strauss and Corbin, 1998). Most qualitative researchers aim to collect enough qualitative data to achieve saturation, which may require as few as 10 or as many as 60 cases, depending upon the quality and quantity of the data available for each case (Small, 2009). Green and Thorogood (2009: 120) recommend that a minimum sample size of 20 is usually necessary to achieve saturation in an interview study: "the experience of most qualitative researchers is that in interview studies, little that is new comes out of transcripts after you have interviewed 20 or so people." To recruit the required number of participants, those who indicated their willingness to participate in this study received participant information sheets and consent forms via e-mail to read, sign, and return to the researchers. Of 47 people who indicated their willingness to participate, 36 participated in the study. In the study sample, there were 19 males and 17 females, aged between 18 and 65 (mean $=34.20$ years, $\mathrm{SD}=9.32$ ). Interviews were scheduled via e-mail. All interviews were audio recorded.

\subsection{Analysis of the Interview Transcripts}

According to Braun and Clarke (2006: 79), "thematic analysis is a method for identifying, analysing and reporting patterns (themes) within data. It minimally organizes and describes data set in rich detail." Thematic analysis enables the researchers to work closely with qualitative data to generate themes that reflect a deep understating of the data that is manifested as a narrative description of the users' experiences. There are six phases in conducting a thematic analysis: "familiarizing [the researchers with] the data; generating initial codes; searching for themes; reviewing themes; defining and naming themes; and producing the report" (Braun and Clarke, 2006: 87-93). Based on these systematic steps, concepts were established. Then, from these concepts, categories were determined that formed the basis for creating a model of Saudi courtship scripts.

\section{Data Analysis}

This paper aims to answer the following research question: What is the script Saudi users follow in trying to find a potential spouse through matrimonial websites? This research illustrates the stages of the Saudi courtship process initiated online. Indeed, Figure (1) illustrates the model of stages of Saudi courtship that involves the use of matrimonial websites. This model comprehensively describes variations the steps towards getting married using one of these sites. The overall process can be divided into ten general stages, discussed in detail in the following sections. Each of these stages comprises a series of decisions on the part of the potential couple. 


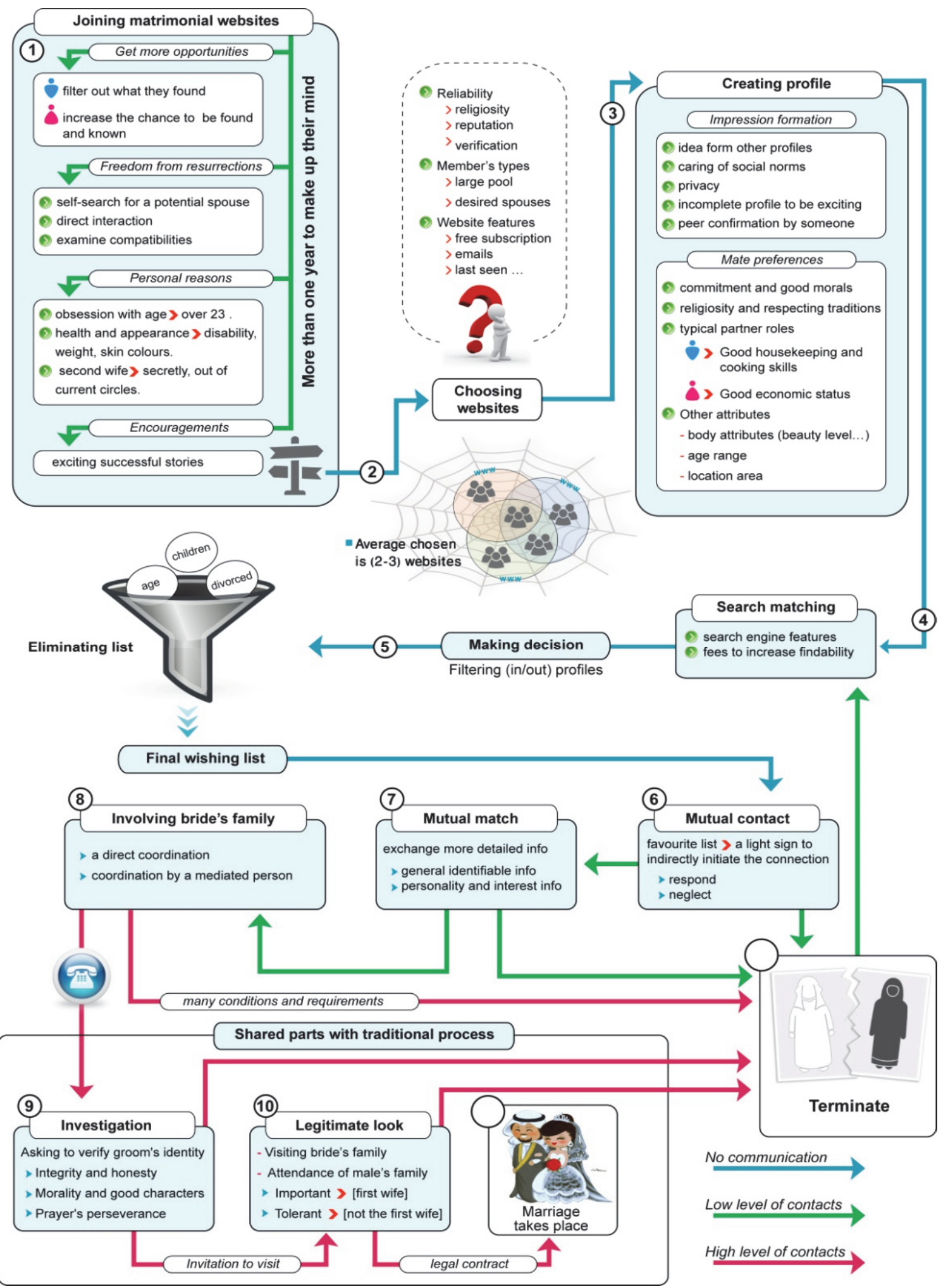

Figure 1. Model of Saudi Courtship

The first stage, (1) in the upper-left region of the model, indicates that marriage seekers are likely to spend more than a year to make up their mind to join matrimonial websites. They take into consideration a number of factors that differ from one person to another: a. more opportunities, b. freedom from restrictions, c. personal reasons and e. encouragement. Once the decision is made to begin utilizing a particular website deemed appropriate using the 
criteria outlined in stage (2), they register and then create an attractive profile in stage (3). The model shows that marriage seekers often use more than one website to expand their pool of potential spouses. This is described by the intersections among groups (circles), as each group represents a certain website, while the elements of the groups are the registered marriage seekers. In addition, a brief description of how and what a profile should contain is illustrated in the top-right of the model, which is zoomed in from a profile's element as an example. In stage (4), a site search engine (basic or advanced) is used to look for serious candidates for marriage. The retrieved search results are usually large and contain many unfavorable profiles, which are filtered using a well-honed list of preferred characteristics in stage (5). With the small group who fits the wish list, the marriage seeker begins the process of communication, which raises subsequent complex decisions. The process of communication, stages (610), heads either to drawing up a legal marriage contract or to terminating the relationship and returning to the search stage (4). The colored lines, ranging from blue to red in the model, represent the level of communication and to some extent the level of attraction between the likely couple. For example, in stage (6), blue and green lines are a low-level connection, representing the initial request to connect that can be confirmed or denied. Early conflicts here always end the connection.

In the next stage (7), communication between potential partners becomes deeper, as each one begins discovering more traits in the other used to make the crucial decision to continue or terminate the relationship. Communication at this stage is usually carried out using private message feature provided by the matrimonial website. Arriving at stage (8) a potential couple wants to investigate more satisfying ways of interacting. Therefore, they need to take a major leap of faith to take further actions and to involve the bride's family in the relationship. This stage tends to be the most difficult one because an intermediary could bungle the process or an authoritative member of the bride's family might oppose it. This would then lead to terminating the relationship. However, if all previous stages go well, the groom or a representative is expected to make a phone call asking for the bride's hand in marriage. It is clear that the process up to stage (8) is a relatively new method of finding and contacting a potential spouse. Despite this, the remaining stages are essentially identical with the traditional method of Saudi courtship. The investigation and then legitimate look stages, (9) and (10), become more formal. All of the details regarding the marriage are expected to be discussed and committed to in advance, before the signing of the marriage agreement.

\section{Research Results}

According to Simon and Gagnon (1986), a script is a mental map that guides individuals' behavior in a potential situation. It consists of a set of actions, learned and culturally enhanced throughout individuals' lifespan. Individuals depend on symbols and descriptions to comprehend their roles in diverse contexts. Contacts that routinely occur are conceived as a determinate sequence of events on which behavior is predicated. Individuals form expectations of behaviors in a setting prior to entering it. To aid in further understanding, grounded theory is also utilized to assist in constructing the emerging model of the Saudi online courtship script. This section displays the steps Saudi marriage seekers take when they use matrimonial websites: deciding to join a matrimonial website, choosing a specific matrimonial website, creating a profile, matching, making decisions, initial and mutual contact, involving the potential bride's family, traditional investigation and legitimate look, followed by preparing for the marriage. Each step includes the criteria they set and the factors that affect their decision-making.

\subsection{Deciding to Join a Matrimonial Website}

The first stage that marriage seekers go through is making the decision to join matrimonial websites or to stick to the traditional methods. The interviewees explained that they spent this duration in observing matrimonial websites and thinking of whether it was worth it to take the next step, weighing the costs and rewards. The rewards that they could gain from joining these sites can be explained in light of the notion of "intrapsychic scripts" that stems from script theory. The intrapsychic script delineates individuals' goals, expectations, and desires, which aids in understanding why Saudis join Islamic matrimonial websites.

This research uncovers four main categories that illustrate the reasons behind joining matrimonial websites: looking for more opportunities, overcoming the limitations of offline interactions in Saudi culture, personal reasons, and encouragement.

\subsubsection{Looking for more Opportunities}

More than the two-thirds of the sample confirm that they are straying from traditional methods because they did not find a suitable spouse that way. Digging in-depth to understand these cases, interviewees stated that online matrimonial websites open new horizons that give users more opportunities to find and be exposed to their matches. Men express that they were tired from knocking on the doors of families of potential spouses and they were disappointed not to find a suitable spouse. For example, (M14) said "My mother and I have knocked at more than 25 houses' doors so far. You know this is our tradition. Your mother or your sister starts to search and asks her 
circles to find you a suitable wife. Everyone has a different opinion about what "suitable" means. Thus, we start our trip by hearing other women's descriptions and when we hear that one girl has characteristics similar to what I am looking for, my mother and I visit her family's house. However, I get tired."

This is not the only (M14) case; most of the men' interviewees have similar stories. (M07), for instance, stated, "When you do not have a young sister in our community, this means that you will struggle to get married. Sisters in their 20s or even 30s make your mission to get married possible and mostly successful. They usually have wide circles of female friends and colleagues, which mean that they have more choices for you. They also can understand your needs more than your mother. I told my mother that I cannot run from one house to another anymore to search for a wife."

Female interviewees, on the other hand, reveal that their role in Saudi courtship is a reaction to men's actions, which means that they need to be exposed to others as a marriage option. Being in a small community with limited circles of relatives and friends makes it difficult for Saudi women to be found. For example, (F12) stated, "I stayed at home after I graduated from high school. Most of my classmates in high school went to universities. One of them is still in touch with me but really I do not think that I will get married through the traditional method, as maybe I am suitable for someone but he does not know about me". (F08) was more explicit and said, "You need to be exposed and known. Nobody knows about you if you keep yourself within your small circle. You cannot knock on a man's door and propose marriage to him. A matrimonial website keeps you more visible to the opposite sex".

The second reason for joining a matrimonial website in this category is to find an alternative to the family and tribal circle. This reason was highly applicable to male participants. More than $60 \%$ of the men agree that matrimonial websites assist them in going beyond their narrow circles. Male interviewees highlight that traditional methods usually come with limited choices. For example, (M16) stated, "Most of women in my family circle are not suitable for me. I am looking for an educated woman who has at least a bachelor's degree. Searching through matrimonial websites give me more options". Looking for more choices and specific characteristics were a concern for some male interviewees. Other participants stress that they want to be free of certain customs and traditions. (M06) indicated that "limited your search within your family circle means that you have to follow some traditions and customs even if you do not believe in them".

On the other hand, most female respondents disagree with the statement that they joined a matrimonial website to find an alternative to their families and tribes. Female interviewees explain why most of the female participants found this statement to not be applicable to their case: finding someone from their own extended family or tribe makes them feel more secure about the relationship. (F13), for example, said, "Finding more choices through a matrimonial website does not mean that you have to avoid your extended family. I prefer to find someone from my extended family, because we can ask about him and know from relatives about his background. This makes me feel safe and comfortable about my future life".

Some women state that having a partner from your family or tribe means that you have something in common, even if it is only traditions and customs. (F06) stated, "I did not join the matrimonial website to find an alternative tribe to my tribe, but to have wider options. I believe that finding a spouse from me tribe increases the compatibility between me and my future husband, as we will have common traditions and customs. Even if some of these traditions are weird, we will have the same weird things to practice".

Few women agreed with the statement that they used matrimonial websites to find alternatives to their tribes, because women traditionally cannot get married to men outside their tribe. (F17) explains, "In Saudi Arabia, some tribes restrict women' marriages to people who have a tribal origin in general, which means that they do not accept men of Hadari origin. Other tribes classify people who belong to tribes into two types; Qabily with high position or 220 and Khadiry or 110. This classification is based on the extent to which a certain tribe has a well-known origin. That means they do not accept men from Khadiry origin to marry their women. Some tribes make their women exclusive to the men from their tribe". This quotation explains why some women do not believe that they use matrimonial websites to find alternatives to their tribes and families, as straying from the tribe could lead to divorce.

\subsubsection{Overcoming the Limitations of Offline Interactions in Saudi Culture}

Hyperpersonal theory contributed to the debate in the Computer Mediated Communication literature regarding the lack of information and social cues in online relationships by highlighting the positive side of asynchronous communication with limited social cues (Walther, 1996). However, this research reinvestigates that argument and examines the extent to which it is applicable to conservative (Shannak, and Obeidat, 2012), Islamic cultures. The results reveal that Saudi users joined matrimonial websites to circumvent the restrictions on offline interactions 
between sexes. Almost all of the participants, representing (90\%) of the men and (93\%) of the women, believe that matrimonial websites enable them to overcome cultural and social restrictions, such as the possibility for both men and women to directly search for a potential spouse, the possibility for direct interaction between sexes, and the possibility to find information about a potential spouse to help determine their compatibility. All of these factors assist in understanding why Saudis choose to use matrimonial websites.

\subsubsection{Searching Directly for a Potential Spouse}

The majority of the sample agrees or strongly agrees that they use matrimonial websites because they want to search for a spouse by themselves (69.5\%). Direct search by marriage seekers is a huge shift in Saudi's courtship process, not only because it removes the mediator role in the searching process but because it empowers both parties in the relationship to direct and manage this vital step by themselves. (M19) stated, "I feel that matrimonial websites provide me something... it is a kind of power that enables men and even women to search by themselves". In addition, matrimonial websites convert women's role from reactive, waiting to accept or reject men's proposals, to active, at least in the searching process. Some participants believe that this feature of matrimonial websites might show how traditional courtship is starting to lose some of its collective attributes. For example, (M09) explained, "It is well known that courtship in our society is a family matter rather than an individual matter. When each relationship party starts searching alone, that means there is a huge transition in Saudis' courtship process".

This transition does not necessarily mean that individuals have complete freedom in this step, as some families even get involved in the online search process for their son or daughter. (F10) stated, "I really appreciate the fact that matrimonial websites' search engines enable me to find potential spouses by myself. However, I prefer to search with my family". (M03) also confirmed this idea: "Although I have the chance to search by myself, I prefer to search with my sisters as I trust their point of views". A few stated that the involvement of their families in their search process is interfering; as (F15) stated, "I have the opportunity to search by myself but my family's questions made me feel that they are watching every single step of my searching process".

\subsubsection{Direct interaction between Sexes}

Almost all of the participants agreed that matrimonial websites make interaction with the potential spouse possible, as well as easier and more comfortable. The literature review clarified the difficulty of interacting with the opposite sex in Saudi society. It illustrated in detail the nature of gender segregation and societal restrictions on approaching unrelated women, which make direct interaction difficult or impossible. These constraints led almost all members of the sample to believe that matrimonial websites are an attractive channel with rich information in comparison with offline interaction (Madini, 2012). (M05) stated, "A matrimonial website provides me with information directly from the main source, my potential spouse. Every single action makes me feel that I am interacting directly with my spouse without a moderator. I value the reaction and silence of the potential spouse and consider them as well as valuable information". (F04) added, "Assuming that you had a chance to interact directly offline with a potential husband, he could not see any of your facial cues because of the hijab. He also could not make eye contact with you, as this is considered an inappropriate behavior in our society. Therefore, I do not think that you will have someone who says that offline [interactions] have richer information than online settings".

Almost all of the participants also agree or strongly agree that online matrimonial websites enable them to provide more information about themselves. By combining this response with the previous responses, it can be said that the Saudi participants believe that matrimonial websites enable them to send and receive more messages and information than in an offline setting. This result contributes to the heated debate regarding the (lack of) social cues in online settings. While hyperpersonal theory altered this debate with the idea that a lack of social cues could be considered a positive side of online settings, as users can be selective in their self-presentation (Walther, 1996), the current result reveals that people from conservative cultures believe that in their cases, the offline setting is the one that lacks social cues. This is especially applicable when it comes to the relationships with the opposite sex. The current research also contribute to the hyperpersonal theory by considering the role of the "message" in online setting and highlighting the differences between the exchanged "message" in Saudi context on one hand and the Western context on the other hand.

\subsubsection{Examine the Compatibility between Two Parties}

There is no way in Saudi traditional courtship to examine the compatibility of the relationship with a partner unless the marriage contract has been signed. Meeting up or having a cup of coffee in a public place are socially unacceptable (Le Renard, 2008). This might provide an explanation why almost all the participants believe that matrimonial websites enable them to have more time to examine the compatibility of a potential spouse. The chance to have a conversation with a potential spouse before marriage is highly valued by Saudi participants. For example, (M11) said, "In my last marriage, the family of my ex-wife did not allow me to talk to her even after the 
Milka ceremony. They told me you can do whatever you want with her once the marriage celebration has finished. However, in a matrimonial website, I can overcome such obstacles". This is also applicable for women; for example, (F16) stated, "I am an educated female who cannot support going through the very traditional courtship process. You know some may say, 'How can you talk to a stranger and have a chat with him?' 'How does your family accept that?' 'It is really a shame'. I really do not care as long as I am using a website to know the extent to which we are compatible to be a husband and a wife".

Saudi users are benefitting from the asynchronous features of matrimonial websites, which give them more time to examine the possibility of compatibility with a potential spouse. They also believe that this feature provides them the opportunity to view other members' profiles or reply to their messages in their timeframe. All of this may explain why Saudi users of matrimonial websites perceive this alternative method of finding a spouse to be more effective than the traditional offline method.

\subsubsection{Personal Reasons}

The third main reason for using matrimonial websites is related to personal issues. These issues include: agerelated pressure, body image concerns, and potential judgment about looking for a second wife. The interview answers reveal that the dominant reason female participants resort to a matrimonial website is fear of their age, which makes sense with the age range of women in the main sample. According to the participants, a Saudi woman starts fearing being too old when she turns 23. For example, (F02) stated, "The Aunousah ghost (an Arabic expression for a spinster) is the main fear for a Saudi girl even if she is under 25. The question sticks in her mind whether she will get married or not... You know, in our society, women in their 30s are not as desirable as women in their 20s. If you are getting old from a Saudi perspective, you should lower your expectations when looking for a husband. You may even agree to be a second wife". (F11), a 26-year-old woman added, "In my family, I am the first child. This puts a lot of pressure on me, especially when men started to ask for marrying my young sister. I feel that I am getting old and that I should find a way to be known and visible in our society so potential spouses can find me".

Concerns related to the body are also part of the personal reasons to use the sites, including having a specific concern regarding one's appearance, having dark or black skin, being overweight, or having a disability. Apart from disability, it seems that women with dark skin or weight issues are unlikely to be successful in the Saudi marriage market. This result emerged from both men and women. For example, (F07) stated, "Though Saudi men do not have white skin and they mostly have olive skin, they really do not like women with black skin. They accept olive and bronze colors as well. But, they really do not like black skin. Maybe you can find someone who likes this color but they are really rare. One of my reasons to be here is to find someone who likes my skin color, as the matrimonial website has a wide pool of people, which increases my chances". Reviewing the preferred color in men's profiles confirms this idea, as more than $60 \%$ prefer white skin. Heaviness is another concern; the description boxes of women's profiles included sentences like "While I have some extra kilos, I am a funny girl". (F03) added, "You know in the early days of the Arab people, they liked heavy-weighted girls. They even wrote poems to describe how pretty they were. Nowadays, heavy-weighted girls should follow a diet to be in-shape and, thus, to be more acceptable by men in our society. This does not mean that there is no one who would like a heavyweighted girl; you may find some but not that much". These findings are in line with a Russian study conducted by Sahib, Koning, and Witteloostuijn (2006) that reveals that being slim is an important trait sought in women in the Russian marriage market.

One of the interviewees had a concern regarding her attractiveness. She stated (F14), "I have a concern about my appearance... especially my nose, as I feel it is a bit big and I really do not know whether men will like my face or not". Another female interviewee (F05) introduced herself as having disability. She stated, "I am here looking for a man who accepts me as a disabled woman, even if he has any type of disability". Such a finding could be explained in light of the concept of "premarital bargaining" proposed by Murstein (1970) in his stimulus-valuerole theory to account for the matching process commonly observed among real partners. He indicates that people who have similar levels of physical attractiveness are more likely to select each other in the dating market.

An interesting additional reason emerged among men related to finding a second wife. Some men indicated that they are looking for a second wife from a matrimonial website because they do not want to disclose this matter to their family or friend circles. (M15) explained, "I am looking for a second wife and I do not want that to be known at this stage. Relatives and friends may blame me and discourage me from going ahead with this step. However, I am really planning to do it". Some men justify this step by stating that they are looking for children, as they waited a long time to have children from their first wives. 


\subsubsection{Encouragement}

Others' stories were a motivation to join matrimonial websites. Nearly two-thirds of the participants in the main sample agree or strongly agree that they have heard success stories about people who used matrimonial websites to find a spouse. This indicates that there are success stories among Saudis who used matrimonial websites and that they are willing to tell their stories. However, interview answers reveal that those couples who successfully get married using a website often fabricate a story to tell their relatives, following the acceptable norms within their circles. For example, (M13) shared, "One of my friends told me that his invented scenario for his relatives is that his sister met his spouse in one of her friends' marriage celebrations and asked for her family". This scenario was repeated in male and female interviewees' answers, which means that some Saudis feel that finding a spouse through a website is stigmatized. They normally disclose the real story to their close friends. That means that the traditional cultural script still has influence among Saudis and some of them may resort to inventing a meeting scenario in line with that script. Viewing online dating as stigmatized matches the results of American studies that show that early online daters did not inform others that they used these websites to find a mate (e.g., Wildermuth, 2004), though recent studies show that such stigma has decreased (e.g., Smith and Duggan, 2013).

\subsection{Choosing a Matrimonial Website to Join}

After making the decision to join a matrimonial website, users start the process of choosing which matrimonial website to join. Interviews reveal that the participants compare matrimonial websites based on certain criteria, similar to a checklist process. Each member has his/her own criteria to filter out undesirable websites. Though personal criteria usually vary from person to person based on their intrapsychic scripts, common themes were repeated by interviewees surrounding looking for a reliable site and checking the types of members and site features.

\subsubsection{Looking for a Reliable Site}

Interviewees stated that they compare different matrimonial websites to find reliable sites, based on the religiosity of the site, website reputation, and verification process.

\subsubsection{The Religiosity of the Website}

The impression that users get when they visit a matrimonial website for the first time is very important. Participants were looking for signs such as a verse from the Quran or a saying by Prophet Mohammed, peace be upon him. (M08) stated, "When you first see a quote from Quran or the sayings by Prophet Mohammed, you can say that this is the first sign that makes you start to consider a website as a respectable one. I know it is not enough but it is still an indication". (F09) added, "It is important for me to find a statement from a website's owner that they follow Islamic instructions". Some participants believe that these kinds of signs are superficial and could be abused by some sites. (M17) explained that "swearing by the name of the God in the registration process, or posting a quote from Quran or the sayings by Prophet Mohammed, or even including some Islamic instructions within the terms and conditions are not actual signs of the religiosity of a website. The design of the website is the one that you can judge". While they belong to an Islamic culture, Saudi users of matrimonial websites seem highly aware that some users may abuse the terms and conditions of the websites even when they fit well with Islamic rules.

Many participants agree with (M02) that the availability of women's photos and the facilitation of relationships outside of marriage are the most real indicators of religiosity. (M12) said, "When you visit a matrimonial website and you do not see women's photos, you can say 'yes' this is the right place that follows religious instructions"'. (F01) stated, "Many websites claim that they are for Saudis and when you visit them, you can tell from the front page that they cannot be for Saudis, because they display a number of women's photos. I believe it is impossible for Saudi women to display their photos in such a way, because they have to conceal them following our religious instructions and traditions". Previous studies among Saudis online reveal that not only in matrimonial websites but also in social media websites, women tend to use symbolic photos instead of their real ones (Aljasir, 2015).

\subsubsection{Reputation of a Website}

Interviewees indicated that the reputation of a website is very important. They were aware that all their disclosed information would be saved and seen by an agent. Therefore, they are eager to deal with the right place. (M12) stated, "I usually start with Googling a website to see what people say about it. I found rich forums with people's experiences and reviews". Other interviewees confirm that forums are considered an important source to find out about a website's reputation. (F16) added, "You cannot trust what you find in certain matrimonial websites' reviews and success stories. They can easily delete negative reviews. However, many forums provide more reliable information". (F03) said, "I read a newspaper report that sheds light on some foreign matrimonial websites that claimed to be suitable for Saudis and then blackmailed their users. Therefore, I resorted to the forums to see 
people's reviews".

Another indicator interviewees discussed is the sites' advertisements. They believe that the number and type of ads provide an idea about the extent to which this agent is reliable. (M18) explained, "Sometimes you feel that the agents of a matrimonial websites do not really care about the matchmaking service. They only concern about gathering a huge number of members and offering anything that could attract people to be on their websites. The platforms of these websites are usually crowded by ads and sometimes you find inappropriate ads".

\subsubsection{Verification Process}

Even though many Saudi matrimonial websites make users promise that their only intention is to find a partner to marry according to Allah and his prophet's rules, as well as promising to be honest with other users, themselves, and Allah, the interviewees believe that these steps are not enough. Some of them believe that this step is not even appropriate. (F15) said, "Day by day, we find people abusing others through these websites despite the fact that they had sworn that they had no intention to deceive people. I believe that maintaining this part of the registration process is abusive to the Islamic religion itself and to the God's name". (M04) added, "There are new techniques that could be used for verification instead of using the name of God and his Prophet peace be upon him".

The interviewees trust websites with a multiple-step registration process more. (F07) said, "When finding a website with only one or just simple steps, you know that this website does not care about the authenticity of its members. I found one website that does not even send a verification email". (M01) added, "Verification steps are really necessary, such as email verification and mobile phone verification steps. I hope that these websites are accredited by the government and even require ID verification to activate the registration of their members".

\subsubsection{Checking a Website's Members}

Saudis look for two main points when choosing a matrimonial site. The first is that a site has a large pool of members, which increases the opportunity of finding a potential spouse. The second is that a site has desired spouses from a user prospective. (F08) said, "In order to choose a website, I view users' profiles and also use the search engine to see whether a website has people I like or not. Sometimes, I find just one or two profiles that fit my preferences. This makes me think of other websites which have more profiles". (M06) provided more details: "For example, I am looking for a Saudi girl who has white skin and is in shape. I will check a website using the search engine; if I find many profiles where female users describe themselves as heavy with dark skin then it is better to find another website".

\subsubsection{The Website Features}

Basic features such as emails, last seen notifications, a section for new members and free subscription options were the most important to interviewees, who believe that some advanced features may ruin a site. According to (M02), "I believe that online chat is not a good feature to have in matrimonial websites. From my experience, websites with online chats usually gather people who are looking for having a relationship or friendship. Meanwhile, restricted websites usually gather people looking for getting married only". Many interviewees confirm this idea and believe offering unrestricted connection is inappropriate. (F13) said she preferred "a more simple, basic, and appropriate website". Such a finding is totally different from Western and East Asian online daters, who appreciate features that facilitate the communication between two parties through online chat or other methods (e.g. Farrer and Gavin, 2009; Jha and Adelman, 2009; Lee, 2009). However, some Western online dating websites take a similar approach and restrict users' access to other members. According to Long (2010), "eHarmony does not allow to browse profiles of other members, and it only sent a handful of matches for review at a time".

Interviewees consider websites that provide both free and paid services a good choice as they can benefit from free services, and if they willing to pay, they can benefit from paid services. Paid services include making a profile more visible and having access to offline matchmakers. No Saudi website provides personality tests or automatching features. Asking interviewees about this result reveals that, because women prefer waiting for men to start the action, paid services offer their profiles more visibility to men than free services.

\subsection{Creating a Profile and Describing an Ideal Match}

The third step of the courtship script is to create a profile on a matrimonial website. While previous studies that investigated creating profiles in online dating websites examined self-presentation (e.g. Whitty, 2008) and the interaction between users and the websites (e.g. Long, 2010), this study is concerned with impression formation and mate preferences. This includes how the sender constructs the profile and how his/her perceptions as a receiver affect his/her intrapsychic script of building an ideal profile. It also includes Saudis' preferences in a potential spouse and the extent to which they resemble or differ from those described by Buss and Schmitt (1993). The study 
combines quantitative and qualitative data to explore the personal scripts of Saudi users, beginning here with impression formation and mate preferences.

\subsubsection{Impression Formation}

One of the main reasons for using hyperpersonal theory in the current study is that it provides an explanation of impression formation in Saudi matrimonial websites based on the written text in online settings, given that Saudi matrimonial websites restrict displaying photos in users' profiles. It also assists in explaining the role of communication components (i.e. sender, receiver, channel and feedback) in the impression formation process (Walther, 1996). The research proved that the online channel conveys more information and rich messages than a traditional courtship setting. As the Saudi matrimonial websites restrict displaying members' photos, the written text and available cues are considered the main source of self-presentation used to form an impression. The qualitative study examined the criteria for forming a favorable impression when Saudi users create their profiles.

\subsubsection{Comparison with Other Users' Profiles}

Before creating a profile, users start by comparing profiles of their gender, and then the opposite gender. They stated that they examined the impression they obtained from others' profiles and observed the description boxes of profile creators and the boxes describing their preferred attributes in a spouse. (F01) explained, "I went through more than 30 women's profiles to see what they include and how they present themselves. Description boxes are different. Some of them are short and some are long. However, the selection of the words and the presentation of the attributes were my main concerns. I even turned to men's profiles and checked out at least 10 profiles and took some ideas from them". Some participants state that observing and comparing profiles is a very important step. They look for the profiles of people with similar characteristics to see how they present themselves in an effective way. (M11) stated, "Browsing members' profiles that have similar attributes and preferences in their future spouse is very important. When I viewed members' profiles I took notes, as some of them reminded me of further important attributes that I should look for in my spouse. I also learned how to leave a good impression through my own profile".

\subsubsection{Respecting Social Norms}

The research reveals that Saudi users, as strategic receivers, believe that respecting social norms is important when filling in the blanks about the profiles of other members in matrimonial websites. The interviews confirm that and clarify the extent to which Saudi users try to remain within traditional social norms. Women were more concerned about being in line with traditions and presenting themselves in an acceptable form to leave a favorable impression. (F04) stated, "As a woman on a matrimonial website, you need to be very careful. The content of the profile includes words, faces and full stops that provide a meaning. This meaning should not cross the lines drawn by our society or provide an unfavorable impression. These issues are part of your reputation and how people see you". Another female, (F06), added, "Explicit family name is considered too much information to provide; even though men like to know more about their potential wives, they do not accept having such information in their profile". It seems that women are concerned with how Saudi men perceive what they present in the profile and what is acceptable and not acceptable. Unlike Western online dating users who look for attractive names when searching for a potential mate (Whitty and Buchanan, 2010), a male participant (M08) clarifies Saudi men's point of view when browsing women's profiles: "You are searching for a wife. She is not a girlfriend. She is the mother of your future children. You need someone who respects our traditions and norms and someone who takes care of her reputation. Thus, sexy names or sexual indications in the description boxes are highly unacceptable". Most of the interviewees shared this opinion. This is to say that men care more than women about the behavior of other members being in line with the social norms when searching for a suitable spouse.

\subsubsection{Privacy Concerns}

Saudi users were aware of the importance of protecting their privacy. Their concerns fell into two types, protecting their privacy from the agent and from other site members. They believe that even though there are some respectable matrimonial websites, there is no clear accreditation process for these websites from government agents. This means that their information could be abused and they do not know who exactly is responsible for their information. Such a concern could also apply to other online settings. Several costs have been identified as the result of disclosing such information. Gross and Acquisti (2005) identify three such costs, involving the hosting site, the user's friends, and third parties. The hosting site, in this case the service providers, can easily access users' information and collect data about them. Members of the website can misuse disclosed information, which could lead to online stalking, bullying, stigmatization, identity fraud, criminal charges, and sexual predation. Finally, third parties, from hackers to governmental agencies, can access a user's information for their own purposes with or without the hosting site's direct agreement. 
(M14) stated, "Even if we agree that a certain website is a respectable one, we cannot grantee that this website will not be hacked. We need to take care of our information when we create our profile. We need to reserve some information for our safety". The second type of privacy is protecting private information from profile viewers. Interviewees' main concern there is being identifiable. For example, some participants working in the educational or military sectors stated that they do not want anyone from their workplaces to identify them. Women fear being identified by one of the members of their family circle.

As Saudi matrimonial sites warn members, especially women, against providing personal contact information in their profiles. Participants respect the need to state this within the terms and conditions of the site but believe not all members adhere to it.

\subsubsection{Missing Information is Tempting}

Completing all the required and non-required information in the profile and filling in the blank boxes with long description were not favorable from interviewees' points of view. They believe that it looks boring and nobody would read all of these things. (M04) stated, "Some members fill all the boxes with long descriptions. I really do not like these profiles and I do not even try to read what they have written. I feel tired even from the look of the profile". Interviewees also believe that a member needs to hold some information back for the coming steps. Concealing some information in a way that attracts readers' attention is also a means of leaving a desirable impression. Female interviewees emphasized this more than males. (F09) stated, "You need to conceal some of your background information to attract viewers' attention and make them read your profile. You then make an opportunity for your potential spouse to discover you and your personality gradually". From interviews, it seems that Saudi women compensate for the lack of photos in their written text without defying traditions, emphasizing their sexuality or providing too much detail about their body shapes. This finding is to some extent in line with hyperpersonal theory, as it assumes that online receivers fill in missing information with their imaginations (Walther, 1996).

\subsubsection{Peer Confirmation}

Saudi users were selective in their presentation of personal attributes. The interviewees stated that they tried to be accurate in their self-descriptions and not deceive profile viewers. (F14) explained, "I understand that if I exaggerate in describing myself, I will disappoint someone who asks for me when he gets to know me in person. Therefore, it is better to be yourself but to provide [information about] yourself in a reasonable way". Most of the participants, men and women, stated that they show someone their profiles or the information they aim to display in the profile to gauge the extent to which these attributes represent themselves. (M18) stated, "I really do not like to disclose that I am on a matrimonial website but I have written my attributes on a paper sheet and showed it to one of my friends to give me his opinion. He made some modifications on what I wrote". (F12) stated that she consulted one of her very close friends to check the accuracy of her profile and get suggestions in presenting herself in a favorable way.

\subsubsection{Mate Preferences}

The qualitative data in this research clarify the following result:

\subsubsection{Commitment and Moral Characteristics}

One of the important factors that men and women look for in a spouse is morality and commitment. Male interviewees expressed their concerns about potential spouses' previous relationships, which arise from Arabic norms and customs. This may explain why morality and commitment were the most important factors for Saudi men. (M12) explained, "We are in a marriage process. That means we are looking for a spouse that protects our honor. She is our Ired and Sharf. Therefore, I am keen to state the importance of chastity and loyalty when writing about my spouse's attributes". (M01) added, "I hope that I find a spouse who had not had a previous romantic relationship. We are in a segregated community and I really worry about the girl that had challenged these norms and had a previous relationship with the opposite sex". This statement is in line with what has been explained in the literature review, that the only acceptable romantic relationship between men and women is a marriage (Aljuhani, 2005). On the other hand, women's understandings of morality and commitment were more focused on the extent to which the potential spouse would respect the marriage. They link men's religiosity, willingness to invest, and desire to have children with his level of commitment. Therefore, they state these attributes in their profiles.

\subsubsection{Typical Partner Roles}

Male interviewees continue to prefer a spouse willing to carry out the typical Saudi female role, highly valuing home-oriented women with housekeeping skills. (M16) explained, "I would really love to find a spouse that can 
take the house responsibilities; from taking care of the children to good cooking”. Good cooking recurred many times in male interviewees' answers. Some male interviewees showed their tolerance of performing these tasks to show that they can cooperate with their partners in such duties. On the other hand, women preferred partners with high earning capacity who can take care of the family expenses. This is a typical male role in Saudi culture that derives its legitimacy from Islamic instructions. Men are obligated to take responsibility for family expenses even if wives have their own incomes. Some female interviewees stated that they do not mind sharing family expenses with their husbands. Interviewees' answers indicated that traditional male and female roles remain priorities for Saudis. However, some of them showed their tolerance toward assuming other roles, women more than men.

\subsubsection{Religiosity and Respecting Traditions}

Initially, the dress code in Saudi Arabia obligates women to wear hijab (Madini, 2012). The most common hijab type among Saudis covers the face. However, there is a trend among Saudi women to cover their hair without veiling their faces. Saudi men were more concern than women about potential partners having a religious look and varied in their preferences between covering faces and wearing modern hijab. (M05) stated, "It is very difficult to marry a woman that does not wear Nigab. All my family's female members cover their faces. I do not know how I could go out with a woman that does not cover her face. Neither my family nor my friends would accept that". Another man, (M13), stated, "I hope that I can find a wife who is an open-minded and uncovers her face. I do not want her to not wear the hijab at all, no, but to wear it without covering her face. My family does not interfere in such decisions". From participants' answers, it seems that social norms control the type of hijab preferred. On the other hand, religiosity from Saudi women's point of view is about behaviour and not only appearance. Many women stated that they wrote in the preferences box in their profiles that they want a husband who fears God and takes care of Islamic obligations. Reviewing the interviewees' profiles confirms that men write about religious appearance and female write about religious behavior, with both indicating the importance of praying every day. This result fits with the findings of a study by Badahdah and Tiemann (2005), who conducted a content analysis of online personal advertisements for Muslims living in America, and with the results of Mishra, Monippally, and Jayakar's (2013) study examining the sexual strategies of Indian Muslim men and women in online matrimonial advertisements. All confirm that users of Muslim matrimonial websites look for a spouse with religious attributes.

\subsubsection{Other Attributes}

Some attributes were mentioned by interviewees, such as body attributes, age range, and geographic area. Men were more likely than women to mention specific body attributes such as body type, skin color, and beauty. The most repeated skin color sought by men was either white or light olive, and a slim or medium build were also among their preferences. Reviewing profile description boxes through the content analysis confirms that these are desired attributes among Saudi users. A few women also stated that they want a good-looking partner. Some men indicated that the location of their potential partner is important, justifying that by stating that they are in an online setting and may find someone suitable for them from a distant geographic area. Therefore, they believe it is important that their potential spouses know that they cannot move from a certain city because of their work or extended family.

\subsection{Matching}

Buss and Schmitt's (1993) theory was a suitable base to explain the strategies Saudi men and women follow when they write their preferences about a potential spouse. After completing and setting the profile to be viewed by other members, marriage seekers start the process of finding their match. While the matching process in Western websites either entails auto-matching after completing certain steps and tests or manual matching by the members themselves through site features (eHarmony.com, 2015), Saudi matrimonial websites do not have an auto option. They mainly depend on search engine features. According to script theory, each member has an intrapsychic script about the attributes of a potential spouse (Simon and Gagnon, 1986), and in the search process, he/she calls upon a certain image of a desirable partner based on the seeker's shopping list.

Interviewees stated that they either use normal or advanced search engines, or subscribe to a paid package that provide them more chances to find their matches by making their profiles more visible on the site. (M07) stated, "The general search engine is helpful in accessing available profiles that match your own criteria. It consists of the following items: nationality, living country, age range, relationship status, and the order of the results. I always keep the nationality and living country items on the Saudi Arabia setting. I set the range for the age to be between 20 to 25 years old and select single in the relationship status's bar. I also set the order of the results bar to the latest online members". In the general search engine, the main criteria among Saudi members are the age range, relationship status, and the order of the results. Based on script theory, the criteria made available by the site are considered within the cultural script, which may affect the search and match process of the members (Simon and 
Gagnon, 1986). Interviewees stated that they play with the available options in the general search engine and filter out undesirable results by changing the age range or reordering the results to see new subscribers. When members engage more in searching process they use the advanced search engine. (F10) explained, "The advanced search engine includes more criteria; the city, marriage type (i.e., if a woman accepts to be a second wife or the only one and if a man wants a first wife or a second one), weight, height, skin color, qualifications, and income". Although some criteria are more important than others, users started with the general search engine at the first stage and then moved on to more details with the advanced search engine.

Men's first two important criteria are within the "spouse attributes box" (i.e. paternity confidence and commitment), which means that they cannot set the advanced search engine based on them. Therefore, the most important criteria they need to set are related the age and the level of attractiveness, and then they move on to profiles to see which ones match their shopping list. On the other hand, women's first criteria are within the advanced search engine options (i.e. ability and willingness to invest), which means that they can search directly for the income criteria and qualifications.

\subsection{Making Decisions}

At this stage, decision-making becomes intertwined with the search process. Marriage seekers either keep the profile for further examination and contact or eliminate it. The decision is based on meeting their criteria and the impression they get from the profile content and self-presentation. Members have their own list of deal breakers that clearly contradict with their intrapsychic script. While filtering mechanisms on Western dating websites start with judging members' photos (Whitty, 2010), members attributes are the available alternative and the first thing to be examined by Saudi users. The list of deal breakers varies from user to user. For example, (M19) states, "The age range and relationship status is very important. I eliminate the profiles that stated that the member is above 28 old. I also eliminate divorced and widowed women from my list". (M10) stated, "I like the white skin and slim body. These attributes are very important to me. Therefore, I eliminate black and dark skin and the heavy-bodied members". (M09) also said, "One of my deal breakers is to have a low level of education, such as profiles of the members with middle school or even high school degrees". Women's deal breakers have some overlap with men's. For example, (F05) stated, "I am 34 years old and I do not mind if I get married to a divorced man, but one of the important criteria for me is that he does not have children from his previous marriage. Therefore, I eliminate divorced men with children". (F17) said, "I start by eliminating men who are looking for a second wife. I cannot accept being a second wife". Women interviewees stated that they also eliminate profiles that indicate their potential matches do not have a career or are currently unemployed.

The second step in eliminating matches is based on the impression users get when viewing profiles. They creatively judge the personality by filling in the blanks from their own point of view by examining the content, language, and available cues (Walther, 1996). Interviewees make it clear that they are looking for marriage, which means that respectable members would not put any sexual indications into their profiles. (M15) stated, "It is highly unacceptable to find a profile that contains inappropriate indications, such as providing too many details about sensitive body parts, talking about intercourse, or even joking about these things". Male users perceive some indications of feminine attributes as inappropriate as well and consider them light sexual indications. They do not consider it a way of obtaining attention but an unacceptable violation of traditional norms. Women also see sexual indications as inappropriate and eliminate such profiles. (F02) said, "If you see a profile with sexual indications and select it for further communication, then you have no one to blame but yourself if he starts abusing you". While it seems that, from Saudi men's perspective, sexual indications are related to the match's level of seriousness and readiness for commitment, Saudi women link it with the possibility of abuse. However, both men and women agree that this red flag is enough to eliminate a profile. This result contradicts with the findings of Western online dating research that reveal that sexy photos and names are acceptable as long as they are not exaggerated (e.g., Whitty, 2010). Users examine word selection and what users sought to convey and make their decisions based on their own criteria to reject or keep the profile for the coming step. (M03) said, "When you read the profile and think of the words and ideas a member uses, you can decide whether to eliminate the profile or keep it. Sometimes you feel confident and you have a clear decision that you are going to eliminate this profile and sometimes you keep it for further investigation". (F01) added, "I think the structure of the sentences, the choice of words, and the style of delivering the ideas affect your decision. You feel confident either to pass on the profile or keep it". It seems that users perform their own analysis based on their culture, background, and desires to form positive or negative impressions towards certain profile.

\subsection{Initial Contact and Establishing Mutual Connection}

At this stage, users have a number of profiles that they aim to pursue with further contact. The research reveals 
that men initiate the action by contacting their potential spouses more than women do. Interviews complement this finding and reveal that when women are interested in a certain profile; they add it to their favorites list, which shows the man that they are interested in him. This subtle action is a sign women prefer to send rather than directly initiating the connection. Waiting for the man to take action or even pay fees to be seen are in line with the traditional Saudi courtship script. As a woman in Saudi traditions should wait for a man to ask for her (Al-Khateeb, 2008), it seems that this norm has been conveyed to online settings as well. Interviewees agreed that the form of the first contact is important in leaving an impression on the potential partner. Therefore, they prefer gradual and mutual contact. (M17) said, "I prefer to start by adding the profile of a woman that I initially like to my favorites list and wait until she visits my profile or becomes online. Then, I start sending her private messages". Users prefer the timing of first messages to be early; however, when they start mutual communication, interviewees have different opinions regarding the timing of messages. Some of them believe it is asynchronous communication and the receiver can reply in his/her own time. Others believe that the relationship is still in the first stages and so it is better to be careful about timing.

From interviewees' answers, mutual contact starts with a man introducing himself and receiving questions from the woman. If the contact was initiated by one party, the other party has the choice to either respond or neglect the communication based on his/her own criteria. Users indicate that they prefer to check the sender's profile before responding to see the extent to which it meets their criteria. If they decide not to continue with this member, then they either neglect or politely show their rejection. Interviewees showed their concern regarding how to reject politely. (F08) explained, "If I found the profile of the member to be not suitable for me, I try to neglect it and the other member usually understands that. But in some cases they still wait for my response... then I feel 'Ooh-how to respond to them.' But, finally I find suitable and polite words indicating that they may find a better match than me or something like that". On the other hand, the message's receiver may decide to go forward. Some participants stated that in their first days on the website, they were more cautious and neglected many private messages but slowly they started to be more natural and responded politely.

\subsection{Mutual Match}

After eliminating undesirable profiles, users keep a small number of profiles for further communication to examine the possibilities of a mutual match. In this stage, users exchange more detailed information, after assuring themselves of the seriousness of the other party. Determining the seriousness of the potential partner is the main concern for both men and women before sharing their private information, to avoiding giving it to the wrong person. Members use their own skills to examine the level of seriousness of other members. (M04) stated, "You can distinguish between serious and curious members. Their questions and style of communication lead you to know the difference". (F09) said, "Some members add you to their favorite lists and start sending you messages but you can tell that they are not serious. Serious members are usually straightforward". Mutual match is an advanced step compared with the previous one as it includes more information. According to Sprecher (2009), a "real relationship" cannot be considered to exist unless there is "mutuality" and "interdependence" between the two partners. Characteristics of this stage are "interdependence", "self-disclosure", "investment in each other", and "a feeling of couple identity" in order to reach full mutuality.

Although more information is disclosed in this stage than before, it is not identifiable information. For example, (F12) stated, "I provide some important but general information about myself, such as, 'I belong to a tribe that lives in Al-Tayief city.' Such information is important to have an idea about my origin but other members cannot identify me or my tribe as there are many tribes which live in this city". According to interview answers, members provide two types of information: general identifiable information and information related to their personalities and interests. They feel comfortable when they exchange the same level of information. (F17) explained, "Though I try to provide general information in the early messages and focus on common things and personality traits, I feel more relaxed when I provide personal information and I receive the same from other members". This strategy of disclosing personal information could be understood in light of social penetration theory which measures the degree of the revealed information according to its breadth and depth. The breadth dimension represents the quantity of the disclosed information and the depth concerns with the sensitivity level of the information. In their social penetration theory, Altman and Taylor (1973) use the 'onion analogy' to explain the process of the selfdisclosure. They indicate that people tend to begin with the outer layers as they only disclose basic information about themselves. When they gain rewards from such disclosure, they start to disclose more inner layers of their sensitive personal information. Such a process is a gradual process as people do not disclose sensitive information about themselves from the initial contact. They protect such sensitive information behind outer until they gain rewards that encourage them to disclose more private information about themselves.

The length of the time is also an important factor to decide whether to continue with the users or reject them. 
Women stress that they feel more confident when they exchange more messages and take more time. Both men and women value the benefit of direct communication with their potential spouse, which is not possible in the traditional courtship script. They assert that they can exchange personal information that enables them to decide whether the other party matches their desires. When exchanging private messages, the participants indicate that they take into consideration the feedback they receive from the other partner to adjust their messages to leave a positive impression. (M10) explained, "When I receive a message, I look to see if the user used smiley faces or has sense of humor. Based on the user's style, I reply". (F11) added, "It is inappropriate to reply to the user who uses serious tone of writing using a humor style. I believe that the elegant user is the one who tries to modify his style of writing based on the sender style". These quotations are in line with Walther's (1996) argument about the mutual effect of this feedback on each partner, which reflects the process of "behavioral confirmation". Behavioral confirmation defines how the receiver's impression of a sender shapes how the sender behaves and how that behavior in turn modifies the reactions of the receiver. Thus, when a sender sends a deliberate self-presentation to a receiver, the receiver idealizes the sender and replies in a manner that positively enhances this self-presented personae. Such a process may lead the sender to modify his/her response according to that feedback.

\subsection{Involving the Potential Bride's Family}

The next phase after establishing a mutual match is to involve a potential brides' family. Female interviewees move to this stage in two ways, with some preferring to coordinate this step by themselves and others preferring to have a mediator from their family or friends coordinate this phase. Interviewees from the first group stated that their families were aware that they were on a matrimonial website and they agreed that it would be appropriate to take the coordination step. On the other hand, some interviewees from the second group indicated that their families were aware of their memberships in the site but not in agreement that they start coordinating process by themselves, preferring a Mahram to coordinate this step. Others stated that their families were not aware of their involvement in a matrimonial site. Therefore, they prefer to disclose this information to one of their close friends or a close member of their family to coordinate this step without informing the family about the site.

Before arranging a meeting, men should provide identifiable information, such as their full real name and the workplace. The next step usually takes place by phone; a man introduces himself to a woman's friend or family member or a potential bride herself. The bride's representatives also introduce themselves after hearing from the groom about his traits and his readiness to take this step, and they exchange their traditional requirements in marriage. The woman's side usually postpones disclosing identifiable information until they are satisfied that the potential groom fulfils their conditions. Therefore, some interviewees stated that they sometimes terminate in this step. Otherwise, when they feel comfortable that everything is going well, they provide the woman's family information and set the time for the traditional investigation process. (M01) said, "I experienced this step several times. The woman's family prefers to first know about you in order to make sure that you are serious and ready for marriage. Some families are also concerned about some traditions, such as the suitability of the tribe of origin or dowry or other issues". (F04) added, "When a potential couple already has concerning answers to the expected questions to be asked by the bride's family before moving toward involving them in the process, the coordination call will then be easy". Women who coordinate a meeting by themselves stated that they take this step to feel comfortable that the potential spouse meets the family's requirements. After that, they either inform their families by themselves or provide a phone number of one of their family members to the potential spouse to ask for them and the set the time for investigation. (F14) said, "I had a bad experience, as I found someone that I thought he was suitable for me but when he talked to my brother by phone he was not ready to answer some questions regarding our traditions, which made him feel offended. Therefore, I start to make sure by myself that a potential spouse is suitable and then inform my family". Female interviewees who have not acknowledged that they are on the site usually find a suitable scenario for their family to involve them. Men consider this an important step, as it is the first stage to take place with the potential spouse's family. The outcomes of the coordination call are either to pursue the next step if everything goes well or to terminate. From male interviewees' answers, it seems that the important reasons that led them to terminate are hearing many conditions and requirements from the bride's family, such as a high dowry and expensive requirements for the marriage or the tribe of origin.

\subsection{Traditional Investigation Process}

This stage is almost identical to the investigation process of the traditional courtship script. When the family receives the potential groom's call and agree with him on general issues, they start the investigation process. This tradition allows them to ask his colleagues and neighbors and people who pray in the same mosque about his behavior, commitment to attending work and praying in the mosque, and whether he smokes. People are obligated by Islamic instructions to answer these questions honestly and they are also encouraged to provide their opinions. Men in this stage do not have any role beyond waiting until they receive the call from the potential bride's family 
either to allow him to visit their home for the legitimate look or to apologies politely. One of the male interviewees who successfully moved to the legitimate look (M06) said, "I heard from some of my colleagues that someone came and asked about me. I realized that these the girl's family members had started the investigation process. After ten days, I received a phone call from her big brother. He welcomed me and said 'We hope to see you and your family next week. Is that suitable for you?". On the other hand, a female interviewee (F16) talked about her experience with this stage and said, "My family started asking about the person after my father spoke with him by phone. Everything was fine. However, when we asked his boss and colleagues about his attitude, they told us that he was absent for a long period of time and that he lacks commitment to his tasks. My Father told me, 'If you want me to go ahead with the marriage process I do not mind, but you may struggle in the future. Maybe he will be fired from his work.' I prayed 'Istekharah' and then said to my father that it is better to reject him politely'. From interviewees' answers, the outcomes of this stage are either to advance and welcome the potential groom with his family or to reject him politely.

\subsection{Legitimate Look}

Male interviewees inform their families either earlier, when they start the coordination process, or after the traditional investigation stage. They need to prepare their family for visiting the potential bride's family. From their answers, it seems that when the man has a concern about his family agreeing, he involves them earlier so he can limit obstacles to the marriage process in the future. Furthermore, coordinating the visit for the legitimate look takes place after the investigation process. The attendance of the man's family is very important when he is looking for a first wife. A woman's family cannot accept excuses for his family's absence that day. If the man comes without his family, they will not allow him to have the legitimate look. (M05) said, "One day, I preferred to go through this stage alone as I found a girl suitable for me and then informing my family about that. However, when I arrived at the potential bride's house, the first question her family asked me was, 'Where is your family?' I explained to them my point of view but they did not accept that. I really started to understand the situation as Saudi families consider the attendance of the family as a sign of seriousness and feel that the family of the potential groom should take part of the responsibility". In the case of a second wife, families are generally more lenient about family attendance. However, women's families prefer that the potential groom attend with someone else, such as a colleague, to share the responsibility with him.

At the day of the legitimate look, the woman prepares herself to be seen by her potential spouse. The man's attendees are not allowed to see the potential bride. Therefore, the legitimate look takes place in a separate room with the attendance of one of her Mahram or the man's mother or sister. The potential bride might bring coffee or juice and stay for a short time, generally no longer than half an hour. Traditions vary in the duration and the nature of this meeting. According to interviewees, many families now allow spouses to sit and talk together for a short time. After the legitimate look, both families wait for the spouses' agreement. The next call between families clarifies the spouses' opinion and whether to start preparing the marriage requirements or go back to the website. The marriage preparation goes through the regular process of traditional marriage. When the couples start this process, they either remove or neglect their profiles. The interviewees said they do not ask their matches to remove the profile. They understand that they as a couple are usually busy at this stage and they will do that when it is convenient. Removing the profile was not an issue for interviewees. Such a finding contradicts the Western dating research that reveals that problems arise between couples if one is discovered to be still actively using the dating website when the other has taken himself or herself off (Whitty, 2010).

\section{Conclusion}

This paper has answered the research question regarding the script Saudi users follow when trying to find a potential spouse through matrimonial websites, providing an in-depth description of the actions and steps these marriage seekers follow. The analysis of the data uncovers four main categories that illustrate the reasons Saudi users join matrimonial websites: more opportunities, freedom from the limitations of offline interactions in Saudi culture, personal reasons, and encouragement. The results also show that Saudi users go through ten distinct stages: deciding to join a matrimonial website, choosing a specific matrimonial website, creating a profile, matching, making decisions, engaging in initial and mutual contact, involving the potential bride's family, making a traditional investigation and legitimate look, and, finally, preparing for marriage. Each of these stages includes the criteria the users set and the factors affecting their decision-making. Answering this question contributes to the literature because it shows the extent to which this relatively new method of finding and contacting a potential spouse differs from the traditional Saudi courtship method. It also contributes to the online dating literature by showing the similarities and differences between conservative Islamic users and Western users who use websites to search for a potential mate. However, an assistant was needed to collect data from female participants during the interview process due to the cultural specificity. Although asking for a female assistant was necessary because 
it was difficult to collect such data from the female participants directly, the researcher was keen to have a high level of agreement when conducting the interviews. To maintain the same level of quality, extra effort was required. The researchers and their colleagues developed specific techniques for asking questions and setting prompt questions to encourage the participants to talk about the phenomenon. In addition to conducting a pilot study, they also tried to anticipate the participants' conditions and their reactions to each question to follow the same techniques. Consequently, more research is needed to validate the current research findings.

The current research has provided an illustration of Saudis' use of matrimonial websites by investigating the sample's impression formation, mate preferences, and scripts of the courtship process initiated online. The study's findings are significant given the scarcity of previous studies examining the usage of Muslim matrimonial websites and online courtship scripts. The research presented here shows the impressions that Saudi users intended to create when constructing their profiles on matrimonial websites, the characteristics said users seek in their potential spouses, and the acceptable Saudi script for courtships initiated on matrimonial websites. Investigating these issues allowed for the construction of a model of this new form of the Saudi courtship process. Although the results of this research show that the dominance of social norms and religion has been transferred to relatively new online ways of finding a spouse, the findings also show that Saudis are currently in a transitional stage, because they have made decisions and found opportunities that did not previously exist in the traditional Saudi courtship process. It seems that online connectivity may create new challenges in the future for the conservative, gender-segregated Saudi culture. The present study contributes to the literature by elaborating upon the Saudi online courtship script, including an in-depth description of the actions users take when seeking a spouse: deciding to join a matrimonial website, choosing a specific matrimonial website, creating a profile, matching, making decisions, creatingand responding to initial contact, getting the potential bride's family involved, setting up the traditional investigation and legitimate look, and, finally, preparing for the marriage. The script starts online, which is a massive change in the Saudi courtship process because it allows men and women to control the process and directly interact with one another. However, users found ways to attend to social norms and religious factors in this unconventional space. When moving offline, the courtship script is almost the same as the traditional courtship script. In addition, although there are numerous Saudis who use matrimonial websites, using these websites seems to be stigmatised, because some users hide their use of the websites or invent an offline scenario when they successfully get married through these websites.

Early scholars in the field of computer-mediated communication (CMC) have based their arguments regarding online relationship development and impression formation on the lack of information and social cues in online settings compared with face-to-face settings. Cues-filtered-out perspective theorists, for instance, argue that CMC reduces social context cues and nonverbal cues, the absence of which is said to deter interpersonal formation of impressions and relationship development. From this perspective, CMC would be anticipated to be less socially oriented and more impersonal in comparison with offline settings (Sproull and Kiesler, 1986). When comparing impression formation in offline and online settings among conservative Saudi Muslims, however, it can be said that the offline setting is the one that lacks social and nonverbal cues between the sexes. This occurs because Saudi females are obliged to cover their whole body with the hijab, and many Saudi females also cover their faces. Further, unrelated sexes have limited acceptable offline interaction with each other. Thus, it could be argued that an online setting could carry more information for Saudis than face-to-face meetings because an online environment would enable users to have more intensive interaction than face-to-face meetings. Furthermore, Saudis can construct and shape their own profiles to create a certain impression of themselves as well as to indicate their preferences in future spouses, which is a relatively new experience for most Saudis. Thus, further research is required to analyse members' profiles that could provide a better understanding of the characteristics of those who choose this relatively new method for finding a spouse. This could be conducting a content analysis to study Saudis' profiles. This approach would allow researchers to deal with the information displayed on the users' profiles. Indeed, previous studies have tended to target the most-visited websites in a field, finding them through the Alexa website, which provides up-to-date information regarding the traffic rank of websites worldwide according to category, subcategory, or country; it also analyses the websites' visitors according to their demographic variables (Tetali, Bose, and Arif 2013; Tarhini et al., 2017). Consequently, researchers need to validate the current research findings by longitudinally examining changes over time regarding the use of matrimonial websites.

Because this research was conducted in Saudi Arabia, it was done in Arabic and translated into English. Thus, it was expected that some translation errors could arise. According to Shiyab (2006), the vagueness related to the usage of colloquial Arabic, idiomatic expressions, patterns of thought, and linguistic devices that mirror the cultural background of Arabs cannot simply be translated from Arabic to English. To overcome this linguistic challenge while taking it into consideration, a back-translation approach was used throughout this study. Liamputtong (2010) 
states that this approach is usually adopted instead of the single-translation approach in social science research to lessen the errors resulting from the translation process and maximise the correspondence between the original language and the targeted language. Thus, the researchers collected and analysed the data in Arabic. Then, the reported results were translated into English and then back to Arabic. This back-translation approach is based on the notion of conceptual equivalence that emphasises the equivalence of the ideas at the sentence level and discourages the verbatim translation of linguistic units (Hilton and Skrutkowski, 2002). Consequently, more research is needed to validate the current research results.

In-depth research is needed in different Arabian countries, because it might reveal that Saudi matrimonial website users could be highly strategic in lessening potential partners' exposure to their undesirable attributes. While singles and educated users might be more cautious about maintaining their images and de-emphasising their negative attributes, religious users may present both their positive and negative qualities more accurately. The negative association between selective self-presentation and religion will possibly be understood considering Islamic instructions regarding accuracy in the courtship process.

\section{References}

Al Azmi, N., Al-Lozi, M., Al-Zu’bi, Z., \& Dahiyat, S. (2012). Patients attitudes toward service quality and its impact on their satisfaction in physical therapy in KSA hospitals. European Journal of Social Sciences, 34(2), 300-314.

Al-Anzi, F. (2009). The role of the ways of thinking, partner selection criteria and some demographic variables to achieve the level of marital adjustment among a sample of Saudi society. Unpublished PhD dissertation. Mecca, KSA: Umm AlQura University.

Al-Duhaish, A., Alshurideh, M., \& Al-Zu'bi, Z. (2014). The impact of the basic reference group usage on the purchasing decision of clothes (A field study of Saudi youth in Riyadh City). Dirasat: Administrative, 41(2), 205-221.

Aljasir, S. (2015). An investigation of Facebook usage by University students in Saudi Arabia. Unpublished PhD dissertation. Coventry, United Kingdom: Coventry University.

Aljuhani, A. (2005). Marriage problems in Saudi society from the perspectives of wives who call the consultation unit. Unpunished MA thesis. Riyadh, KSA: Naif University.

Al-Khateeb, S. (2008). Women, family and the discovery of oil in Saudi Arabia. Marriage \& Family Review, 27(12), 167-189.

Al-Lily, A. E. (2011). On line and under veil: Technology-facilitated communication and Saudi female experience within academia. Technology in Society, 33(1), 119-127.

Alnajrani, H., Bajnaid, A., Elyas, T., \& Masa'deh, R. (2018). Exploring the transitional era in Saudi Arabia journalism discourse and the path towards the right to freedom of expression. Modern Applied Science, 12(10), $1-12$.

Al-Romi, A., \& Al-Saeg, A. (2004). The marriage in Saudi Arabia: A comprehensive study for marriage issues. Riyadh, KAS: The ministry of social affairs.

Al-Saggaf, Y. (2013). Males' trust and mistrust of females in Muslim matrimonial sites. Journal of Information, Communication and Ethics in Society, 11(3), 174-192.

Al-Saggaf, Y., \& Weckert, J. (2004). The effects of participation in online communities on individuals in Saudi Arabia. Computers and Society ACM SIGCAS, 34(1).

Altman, I., \& Taylor, D. (1973). Social penetration: The development of interpersonal relationships. New York, NY: Holt, Rinehart and Winston.

Badahdah, A. M., \& Tiemann, K. A. (2005). Mate selection criteria among Muslims living in America. Evolution and Human Behavior, 26(5), 432-440.

Bajnaid, A., \& Al-Saggaf, Y. (2017). Impression formation on matrimonial sites. Proceedings of the 29th Australian Conference on Computer-Human Interaction (pp. 77-86). ACM.

Bajnaid, A., \& Elareshi, M. (2018). Personal characteristics of Islamic matrimonial website users in Saudi Arabia: an empirical study. Journal of Arab \& Muslim Media Research, 11(1), 83-101.

Bajnaid, A., \& Elyas, T. (2017). Exploring the phenomena of online dating platforms versus Saudi traditional spouse courtship in the 21 st century. Digest of Middle East Studies, 26(1), 74-96. 
Bargh, J. A., \& McKenna, K. Y. (2004). The Internet and social life. Annual Review Psychogy., 55, 573-590.

Braun, V., \& Clarke, V. (2006) Using thematic analysis in psychology. Qualitative Research in Psychology, 3(2), $77-101$

Buss, D., \& Schmitt, D. (1993). Sexual strategies theory: An evolutionary perspective on human mating. Psychological Review, 100, 204-232.

Darawsheh, S., ALshaar, A., \& AL-Lozi, M. (2016). The degree of heads of departments at the University of Dammam to practice transformational leadership style from the point of view of the faculty members. Journal of Social Sciences (COES\&RJ-JSS), 5(1), 56-79.

Farrer, J., \& Gavin, J. (2009). Online dating in Japan: A test of social information processing theory. Cyber Psychology \& Behavior, 12(4), 407-412.

Green, J., \& Thorogood, N. (2009). Qualitative methods for health research. Thousand Oaks, CA: Sage Publications.

Gross, R., \& Acquisti, A. (2005). Information revelation and privacy in online social networks. In Proceedings of the 2005 ACM workshop on Privacy in the electronic society (pp. 71-80). New York, NY: ACM.

Hammersley, M. (2006). Ethnography: problems and prospects. Ethnography and education, 1(1), 3-14.

Hamon, R. R., \& Ingoldsby, B. B. (2003). Mate selection across cultures. New York, NY: Sage Publications.

James, N., \& Busher, H. (2009). Online interviewing. London: Sage.

Jha, S., \& Adelman, M. (2009). Looking for love in all the white places: A study of skin color preferences on Indian matrimonial and mate-seeking websites. Journal Studies in South Asian Film \& Media, 1(1), 65-83.

Joinson, A. (2001). Self-disclosure in computer-mediated communication: The role of self-awareness and visual anonymity. European Journal of Social Psychology, 31, 177-192.

Le Renard, A. L. (2008). Only for women: Women, the state, and reform in Saudi Arabia. Middle East Journal, 62(46), 610-629.

Lee, S. (2009). Marriage and online mate-search services: Evidence from South Korea. Unpublished Doctoral Dissertation. Maryland: University of Maryland.

Long, B. L. (2010). Scripts for online dating: A model and theory of online romantic relationship initiation. Unpublished Doctoral dissertation. Bowling Green, OH: Bowling Green State University.

Madini, A. (2012). Online communication in a discussion forum for expatriate Saudi Arabian students: Gender issues. Unpublished PhD Dissertation. Brisbane, Australia: The University of Queensland.

Maqableh, M., Rajab, L., Quteshat, W., Khatib, T., \& Karajeh, H. (2015). The impact of social media networks websites usage on students' academic performance. Communications and Network, 7(4), 159-171.

Mirah, D., \& Masa'deh, R. (2014). An analysis of the insurance industry regulator in Saudi Arabia and Jordan through the comparison with insurance industry regulator in the UK. Asian Social Science, 10(3), 211-220.

Mishra, S., Monippally, M.M., \& Jayakar, K. P. (2013). Self-presentation in online environments: A study of Indian Muslim matrimonial profiles. Asian Journal of Communication, 23(1), 38-53.

Murstein, B. I. (1970). Stimulus value role: A Theory of marital choice. Journal of Marriage and the Family, 465481.

Sahib, P. R., Koning, R. H., \& van Witteloostuijn, A. (2006). Putting your best cyber identity forward an analysis of 'success stories' from a Russian internet marriage agency. International Sociology, 21(1), 61-82.

Shannak, R., \& Obeidat, B. (2012). Culture and the implementation process of strategic decisions in Jordan. Journal of Management Research, 4(4), 257-281.

Silvermann, D. (1993). Interpreting qualitative data: methods for analyzing talk, text, and introduction. London: Sage Publications.

Simon, W., \& Gagnon, J. H. (1986). Sexual scripts: Permanence and change. Archives of Sexual Behavior, 15(2), 97-120.

Small, M. L. (2009). How many cases do I need? On science and the logic of case selection in field-based research. Ethnography, 10(1), 5-38.

Smith, A., \& Duggan, M. (2013). Social media update. Washington, DC: Pew Research Center. 
Sprecher, S. (2009). Relationship initiation and formation on the Internet. Marriage \& Family Review, 45(6-8), 761-782.

Strauss, A., \& Corbin, J. (1998). Basics of qualitative research. Thousand Oaks, CA: Sage Publications.

Tarhini, A., Al-Busaidi, K., Bany Mohammed, A., \& Maqableh, M. (2017). Factors influencing students' adoption of e-learning: A structural equation modeling approach. Journal of International Education in Business, 10(2), 164-182.

Tetali, R., Bose, J., \& Arif, T. (2013). Browser with clustering of web documents. In Advanced Computing, Networking and Security (ADCONS), 2013 2nd International Conference on (pp. 164-168). IEEE.

Walther, J. B. (1996). Computer-mediated communication: Impersonal, interpersonal, and hyperpersonal interaction. Communication Research, 23, 3-43.

Whitty, M. (2008). Revealing the "real" me, searching for the "actual" you: Presentations of self on an internet dating site. Computers in Human Behavior, 24, 1707-1723.

Whitty, M. (2010). E-dating: The five phases on online dating. In C. Romm-Livermore and K. Setzekorn (Eds.). Social networking communities and e-dating services: concepts and implications (pp. 278-291).Hershey, PA: IGI Global Publishing.

Whitty, M. T., \& Buchanan, T. (2010). What's in a screen name? Attractiveness of different types of screen names used by online daters. International Journal of Internet Science, 5(1), 5-19.

Wildermuth, S. M. (2004). The effects of stigmatizing discourse on the quality of on-line relationships. Cyber Psychology \& Behavior, 7, 73-84.

Wojnar, D. M., \& Swanson, K.M. (2007). Phenomenology an exploration. Journal of Holistic Nursing, 25(3), 172180.

\section{Copyrights}

Copyright for this article is retained by the author(s), with first publication rights granted to the journal.

This is an open-access article distributed under the terms and conditions of the Creative Commons Attribution license (http://creativecommons.org/licenses/by/4.0/). 